\title{
Deadweight anchoring behavior for aquaculture longline
}

\author{
Ernesto Trujillo ${ }^{1}$, Luis León ${ }^{2}$, Guillermo Martínez ${ }^{3}$ \\ ${ }^{1}$ Instituto de Investigaciones Científicas, Universidad de Oriente, Núcleo Nueva Esparta, Venezuela \\ ${ }^{2}$ Escuela de Ciencias Aplicadas del Mar, Universidad de Oriente, Núcleo Nueva Esparta, Venezuela \\ ${ }^{3}$ Escuela de Ciencias del Mar, Pontificia Universidad Católica de Valparaíso, Chile \\ Corresponding author: Guillermo Martínez (guillermo.martinez@pucv.cl)
}

\begin{abstract}
The similarity theory was used to study the behavior of five anchoring and one "rezon" type deadweight designs, using scale models. The surface sediments extracted from Charagato Bay, Cubagua Island, were characterized to evaluate the efficiency of these models on these substrates. A test structure consisting of a tank with a mixture of sediment and seawater, and a metal trestle was used. Tension variables were considered, using a $6 \mathrm{~mm}$ PE end section. Weights were added at one of its ends which represented the longline system's resistance force and at the other the model's force in the eyebolt (Tc) representing the gripping force due to the interaction of the anchoring design with the substrate, and the static rupture tension (Tr) upon the weight (Pm) of each model, against different anchoring attack angles $(\theta)$, aspect ratios (AR) $1 / 2.5 ; 1 / 3.0 ; 1 / 3.5$, and 1/4.0; sail attack angles $(\beta)$ of 0,10 , and $20^{\circ}$, and the efficiency index (EI) of each model. The Kruskal-Wallis contrast was used to detect the possible differences against different anchoring attack angles, and, to locate the differences between them; box and mustache graphs were used. The most effective model on very fine sandtype sediment was the pyramidal with the claw-like frame, followed by the pyramidal with the shovel-like frame and the "rezon" type traditionally used on Margarita Island.
\end{abstract}

Keywords: deadweight anchors; longline; scale models; theory of similarity; aquaculture

\section{INTRODUCTION}

Anchors are used for stationary flotation anchoring systems, such as fishing gears, larger and smaller vessels, longlines, oceanographic buoys, among others; and they have a diversity of forms and types of materials, their selection being a key aspect in the design of the system in which they will be used. These anchors in a longline culture have as a mission to provide enough gripping power to avoid that it loses its structural form during the operation (Merino, 1997; Merino et al., 2001). For this purpose, Berteaux (1976) studied different types of anchorages made of concrete material and determined that they have a high capacity to respond to the vertical tensions exerted by the flotation of a system. Still, with horizontal stresses, they have a limited grip power at the bottom. In this sense, he determined that the factors that most influence the design and selection are the direction and intensity of the anchoring line tension, the nature of the substrate and its friction coefficient, and the slope of the bottom (Beveridge, 1987; Berteaux, 1991).

Ogg (1969) also determined that the grip strength of concrete anchorages is approximately $50 \%$ of their weight in the air; they are easy to build, inexpensive, and disposable. Among the most common designs are the truncated pyramid type, the parallelepiped, and the wedge type; all of them are vulnerable to lateral displacements because of changes in the direction of currents (Carroza, 1990).

On the other hand, Childers (1973) carried out studies on anchoring systems of the dynamic type for the mooring of vessels on oil platforms and other marine structures. He established that these anchors increase their grip power with the horizontal tension, which allows them to firmly claw in the bottom if there are no vertical thrust forces.

Corresponding editor: Cesar Lodeiros 
There are no particular methods for sizing and selecting deadweight anchors for culture longlines (Martínez \& Carroza, 1992). Therefore, we use experiences obtained in operations with other production systems; many authors have worked in this line of research analyzing the methodologies that best suit the requirements of their projects. Among these authors is Berteaux (1976), who used the physical and engineering concepts and the different types and elements used in anchoring. He described the characteristics of deadweight type systems, embedment anchors, and special anchors.

Likewise, Yokota (1980) structured a method for the dimensioning of rafts anchoring destined for mytiliculture. It consisted of eliminating the deadweight type anchor friction coefficient creating a vacuum to the base exposed to the muddy substrate producing a suction effect, which becomes the necessary force to adhere to the substrate. This feature improves the operation of this model concerning other deadweight types. In this sense, Martínez \& Carroza (1992), supported by some of the authors mentioned above, worked on the anchor dimensioning for longline farming systems. Trujillo et al. (2007) also worked on calculating the tension in the different longline components for the pearl oyster culture, including the tension generated in the five nails "rezon" anchorage subsystem type traditionally used in Margarita Island.

\section{The theoretical framework of scale models}

Voinikanis-Mirskii (1979) states that the model's behavior prediction accuracy depends on the appropriate use of their scales. For this, he establishes three scale types that interrelate the prototype (natural) dimensions with the model. These scales are the geometric scale ( $\mathrm{Lr})$, kinematic scale (Tr), and the dynamic scale (Fr). The evaluation of each type of scale results in three types of similarity: kinematic, geometric, and dynamic.

Regarding the longline hydrodynamic behavior, the shape, position, and balance of this type of structure located in the sea directly depend on the force's magnitude and direction acting on it. Therefore, for every kind of structure, there is a defined pattern for the action of the external forces (López et al., 2017). On this topic, Fridman (1986) divides these forces into gravitational, hydrostatic and hydrodynamic forces (which are the product of the pressure exerted by the body of water on the structure), friction force (generated by the reaction of the seafloor), wave action forces, and additional forces caused by the management of the system (Berteaux, 1976; Baranov, 1977; Fridman, 1981).
It is necessary to emphasize that the loss of the longline system structure's characteristic shape is due to the decrease in the tension to which it is subjected. This alteration causes severe disruptions. Because the mother line, being more flexible, is at the mercy of the currents and collapses, presenting a more condensed area, which increases the anchorage's shifts (deflection or sail effect), with the consequent loss of the bottom and slope concerning the original site selected for its installation. This situation causes a constant movement of the cultivation units and, consequently, the agitation and accumulation of the reared organisms, producing the wrong use of the available cultivation area. These movements bring an increase in the reared organisms' stress levels, due to the agitation that these suffer, increasing the possibilities of mortality in the cultivation process (Carroza, 1990; Barrientos, 2000).

Because the longline is a complex culture system, which requires engineering design to secure the rearing devices, there was interest in studying the grip behavior of six anchoring types, using scale models, taking as reference Carroza (1990), Martínez \& Carroza (1992), Concha (1997) and Barrientos (2000).

\section{MATERIALS AND METHODS}

\section{Materials used in the research}

Sediments were extracted from the intertidal zone Charagato Bay, Cubagua Island, in Universidad de Oriente Research Station front, to study the behavior of five deadweight anchor models and determine their grip efficiency, both dynamic and non-dynamic on this type of substrate, including the five nails "rezon" metal anchor-type as a contrasting element in the evaluation.

A test panel (Fig. 1) was used, consisting of a fiberglass test tank with very fine sand-type sediment $(\approx 0.063 \mathrm{~mm})$, and seawater of approximately $2.64 \mathrm{~m}^{3}$, and a two pillars trestle of iron tubes. An inverted V shape, $2.0 \times 1 \mathrm{~cm}$ each, on which a $2.20 \mathrm{~m}$ in length crossbar was placed, graduated with different fractions, with a sliding pulley at the height of $1.7 \mathrm{~m}$. These fractions allowed to configure the longitudinal angles of attack in the direction $(\theta)$ of $25,20,17$, and $15^{\circ}$, corresponding to the aspect ratio (AR) $1 / 2.5 ; 1 / 3.0$; $1 / 3.5$ and 1/4.0; and the transversal attack angles $(\beta)$ which allowed to simulate the deflection or sail effect. These angles were 0,10 , and $20^{\circ}$.

The iron trestle allowed to simulate the interactions of external forces, equivalent to the tensions exerted by a long line, which influenced the tension in the anchor's eyebolt and the gripping efficiency of five scale models. Deadweight, with its respective geometric and characteristic weight, such as rectangular, simple pyra- 


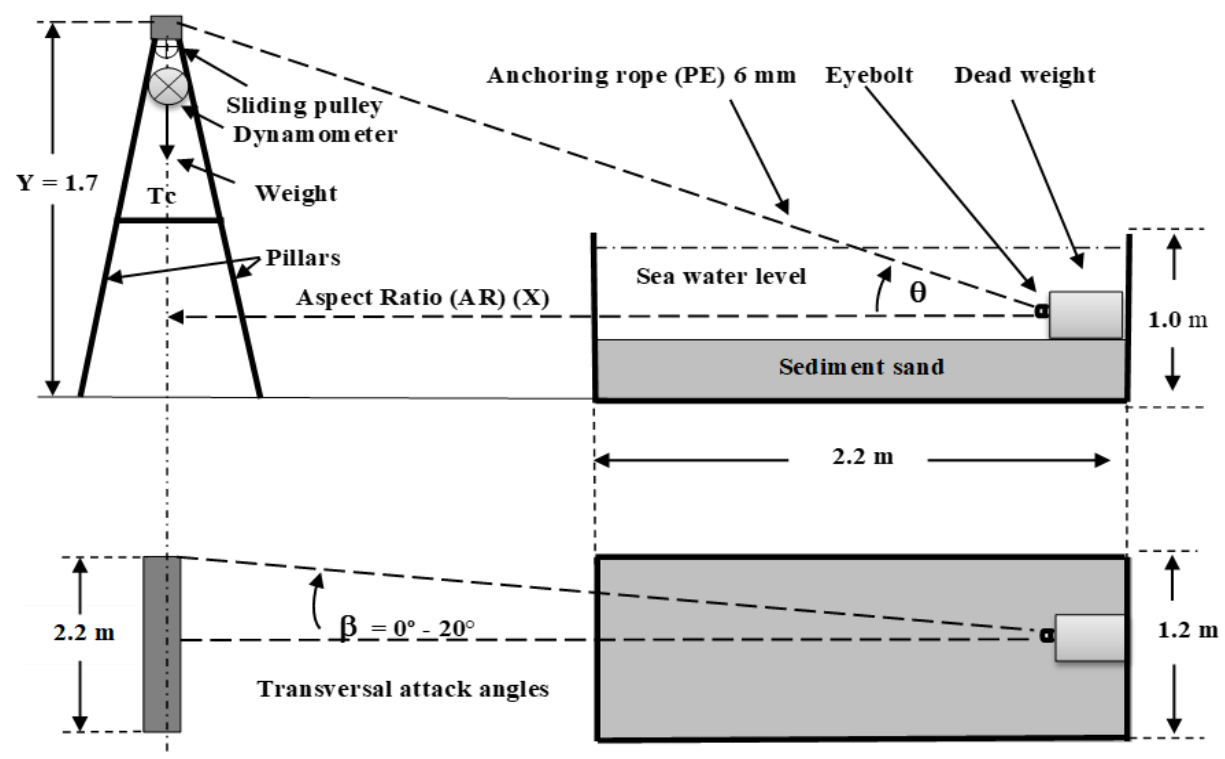

Figure 1. Test panel diagram (Modified from Barrientos, 2000).

midal, pyramidal with claw system, hollow pyramidal, pyramidal with shovel system. The same simulation procedure was carried out of the external interaction forces and the efficiency of grip on the ring in a five nails "rezon" anchor scale model.

Different deadweight scale model's geometric relationships designs were applied to keep measurements proportional to each side, regardless of the scale to which they were subjected. The plans were prepared to have reference to Concha (1997), with the respective measures chosen according to the ease of construction.

Concrete was used to construct the deadweight models, consisting of four parts of sand, one of cement, and two of gravel, providing a density of approximately $2,400 \mathrm{~kg} \mathrm{~m}^{-3}$ (Barrientos, 2000). In the case of dynamic moorings, metal structures in the shapes of shovel and claw were incorporated into the concrete mix. In the case of non-dynamic deadweight moorings, base metal structures were used as an eyebolt. The concrete filling molds in wood-sheet were used based on the scale measures determined in the design for the construction of all the models.

Gravitational forces were used with the help of a container with sand and gravel to produce the tensions in the eyebolt of the model attached, at one end, to a line of $8 \mathrm{~mm}$. Weight records were taken with a strain gauge type dynamometer, which represented the tension in the eyebolt of the model (Fig. 1).

\section{Methods used in the research}

According to the conceptual research basis, the following experimental variables were defined:
- Tension in the eyebolt (Tc). Gravitational forces simulated it.

- Anchoring attack angle (vertical deflection) $(\theta)$.

- In the simulation, angles of attack of 25, 20, 17, and $15^{\circ}$ were adopted, corresponding to AR $1 / 2.5 ; 1 / 3.0$; $1 / 3.5$; and $1 / 4.0$, respectively, where the distance of the model $(\mathrm{X})$ is a function of the height of the pulley $(\mathrm{Y})$ located on the iron crossbar (Fig. 1).

The assumptions and criteria for carrying out the experience were the friction between the model's rope (the sliding pulley was considered negligible). The hydrodynamic magnitude and direction drag vector is the result of the net tension applied to the model eyebolt, generated by the gravitational forces applied at the other end rope. The interaction with the substrate is a product of friction and grip; the greater the model mass, the greater the friction on the bottom.

\section{Sail attack angle (horizontal deflection) $(\beta)$}

In the experience, angles of attack of 0,10 , and $20^{\circ}$ were adopted, simulating the descent (deviation) of the anchoring line and the mother line, relative to the anchoring.

The conceptual basis for the analysis of the test results was created, according to the models' behavior. Thus, the model's displacement (D) concepts and grip efficiency index (IA) were used. The models' displacement, as well as their characteristics and magnitude, was evaluated through direct observation.

The grip efficiency of the model (IA) corresponded to the model's ratio of the net static rupture tension 
$\left(\mathrm{T}_{\mathrm{RE}}\right)$ versus the dry weight of the model $(\mathrm{Pm})$ (Barrientos, 2000). The necessary force was considered for the model to break its hydrostatic equilibrium, and the movement to originate was regarded as the breaking stress. In this way, efficiency was established considering the registered tension's average, about the mass over the substrate of each model, represented by a dimensionless number. Thus, the ratio of the net static breaking stress.

$$
\mathrm{IA}=\mathrm{T}_{\mathrm{RE}} / \mathrm{Pm}
$$

\section{The scale of the models}

For the construction of the model, two similarity scales were established: geometric similarity and dynamic similarity.

\section{Geometric linear scale $\left(\lambda_{\text {Lr }}\right)$}

The linear relationship of prototype anchoring in real scale (Lp) and the homologous dimension of the model (Lm):

$$
\lambda_{\mathrm{Lr}}=\mathrm{Lp} / \mathrm{Lm}
$$

This scale was selected according to the space availability of the installation and the ease of working. This scale is defined by dependence, the magnitude of the dynamic scale, or scale of forces.

\section{Dynamic scale $\left(\lambda_{\mathrm{Fr}}\right)$}

Relationship between the weight of the prototype anchoring (Fp) and the theoretical weight of the model (Fm):

$$
\lambda_{\mathrm{Fr}}=\mathrm{Fp} / \mathrm{Fm}
$$

The theoretical weight of the deadweight model considered had a concrete mix density of $2,400 \mathrm{~kg} \mathrm{~m}^{-3}$, based on the proportions of sand, cement, and gravel previously indicated.

It was determined that the number of repetitions for the tests, for each model, were 10 times (Cochran, 1963).

The Kruskal-Wallis contrast was used to detect the possible differences in the attack angles, and scales of the different models used (Sokal \& Rohlf, 1995), and box and whisker plots were used to locate the differences.

\section{RESULTS}

\section{Defining the scales of the deadweight model}

The linear scale was determined by knowing the geometric relationships, according to two prototypes: a square and a truncated pyramid. We proceeded to define the geometric scale and the dynamics of the selected square type mooring. For the geometric scale of this prototype we assumed $\mathrm{M}=500 \mathrm{~kg}$, square side $=0.637 \mathrm{~m}$, area $=1.435 \mathrm{~m}$, and square volume $\mathrm{V}=$ $0.258 \mathrm{~m}^{3}$.

Likewise, the geometric scale and dynamics of the selected truncated pyramid type prototype anchoring were defined. For the geometric scale, it was assumed $\mathrm{M}=405.25 \mathrm{~kg}$, basis side $=0.637$, area $=1.497 \mathrm{~m}^{2}$ and volume $\mathrm{V}=0.248 \mathrm{~m}^{3}$.

The selected parameter for the basis of the model was equal to $0.20 \mathrm{~m}$.

\section{Geometric scale}

The characteristics of the model were, volume $=0.109$ $\mathrm{m}^{3}$, density $=2,400 \mathrm{~kg} \mathrm{~m}^{-3}$.

The parameter selected for the bases of the model was equal to $0.20 \mathrm{~m}$. According to this, the formulation for the linear scale of the truncated pyramid was:

Geometric scale used $\left(\mathrm{E}_{\mathrm{LR}}\right)=\mathrm{L}_{\mathrm{P}} / \mathrm{L}_{\mathrm{M}}=3.184$

\section{Force scale}

The scale of forces was determined according to the weight characteristics of the prototype, considering a concrete density of $\rho=2,400 \mathrm{~kg} \mathrm{~m}^{-3}$ (Barrientos, 2000).

The selected parameter, for the basis of the square model prototype, was equal to $9.5 \mathrm{~kg}$. According to this, the formulation for the weight scale was:

Dynamic scale used $\left(\mathrm{E}_{\mathrm{FR}}\right)=\mathrm{F}_{\mathrm{P}} / \mathrm{F}_{\mathrm{M}}=52.64$

Similarly, the parameter selected for the truncated pyramid model basis was equal to $7.7 \mathrm{~kg}$. Therefore, the formulation for the weight scale was:

$$
\text { Dynamic scale used }\left(\mathrm{E}_{\mathrm{FR}}\right)=\mathrm{F}_{\mathrm{P}} / \mathrm{F}_{\mathrm{M}}=52.63
$$

\section{On the simulation with scale models}

The tension of the anchor line of a longline for AR: $1 / 2.5 ; 1 / 3.0 ; 1 / 3.5$ and $1 / 4.0$ were determined. In this sense, the vertical angle of attack $(\theta)$ was formed by coinciding with the current direction at an angle of $0^{\circ}$ (current parallel to the mother line), corresponding to $25,20,17$, and $15^{\circ}$, according to the different ARs and, at the same time, the different charges arising from the vertical attack angles $(\theta)$ and the corresponding ARs were simulated, which allowed us to measure the moment of the static break of the anchor.

The sail attack angle $(\beta)$, formed from the angle of $0^{\circ}$, which during the simulation coincides with the current parallel to the mother line, was measured moving the anchorage line at lateral angles (deflection of the mother line) of 0,10 and $20^{\circ}$. These angles were measured simultaneously with the vertical attack angles $(\theta)$. 
Table 1. Efficiency index (EI) of the different deadweight models. AR: aspect ratio.

\begin{tabular}{llccc}
\hline \multirow{2}{*}{ AR } & \multicolumn{3}{c}{ Model } & \multicolumn{3}{c}{ Attack angle } \\
\cline { 3 - 5 } $1 / 2.5$ & Simple truncated pyramid & 0.331 & 0.414 & 0.381 \\
& Simple truncated pyramid with claw & 0.832 & 0.878 & 0.616 \\
& Truncated pyramid with shovel & 1.006 & 0.843 & 0.601 \\
& "Rezon" & 1.277 & 0.822 & 0.533 \\
& Square & 0.624 & 0.532 & 0.315 \\
& Hollow truncated pyramid & 0.160 & 0.192 & 0.132 \\
$1 / 3.0$ & Simple truncated pyramid & 0.614 & 0.596 & 0.431 \\
& Simple truncated pyramid with claw & 1.145 & 0.721 & 0.532 \\
& Truncated pyramid with shovel & 0.755 & 0.697 & 0.597 \\
& "Rezon" & 1.355 & 1.066 & 0.596 \\
& Square & 0.605 & 0.506 & 0.392 \\
& Hollow truncated pyramid & 0.155 & 0.098 & 0.068 \\
$1 / 3.5$ & Simple truncated pyramid & 0.471 & 0.437 & 0.242 \\
& Simple truncated pyramid with claw & 1.135 & 0.631 & 0.605 \\
& Truncated pyramid with shovel & 1.116 & 0.812 & 0.602 \\
& "Rezon" & 1.410 & 1.881 & 1.088 \\
& Square & 0.735 & 0.429 & 0.446 \\
& Hollow truncated pyramid & 0.154 & 0.188 & 0.155 \\
$1 / 4.0$ & Simple truncated pyramid & 0.527 & 0.481 & 0.392 \\
& Simple truncated pyramid with claw & 0.818 & 0.697 & 0.493 \\
& Truncated pyramid with shovel & 0.950 & 0.777 & 0.620 \\
& "Rezon" & 1.146 & 0.992 & 0.648 \\
& Square & 0.735 & 0.429 & 0.457 \\
& Hollow truncated pyramid & 0.273 & 0.253 & 0.192 \\
\hline
\end{tabular}

The tests carried out with the different models, at different AR scales and lateral attack angles $(\beta)$, showed the efficiency index (AI) results for each proposed model (Table 1).

Because the measurement data for different attack angles and scales in the different models did not exhibit a normal distribution, the Kruskal-Wallis contrast (Sokal \& Rohlf, 1995) was used to detect possible differences. Box and whisker plots were used as a posteriori test.

\section{The behavior of scale models}

\section{Simple square model (Adapted from Ogg, 1969)}

For different sail attack angles $(\beta)$ used in the experience, the average weight values were: $0^{\circ}=2.82 \mathrm{~kg}$; $10^{\circ}=2.00 \mathrm{~kg}$; and $20^{\circ}=1.56 \mathrm{~kg}$. The Kruskal-Wallis contrast detected significant differences between the medians of the weights obtained in the three angles $(\mathrm{KW}=84.668 ; P<0.05)$. It was determined that in the three measurements, using the box and whisker plot as a posteriori test, the median of the values differed (Fig. 2 ), being outstanding that greater angles cause greater instability of the model and required little tension to move it.

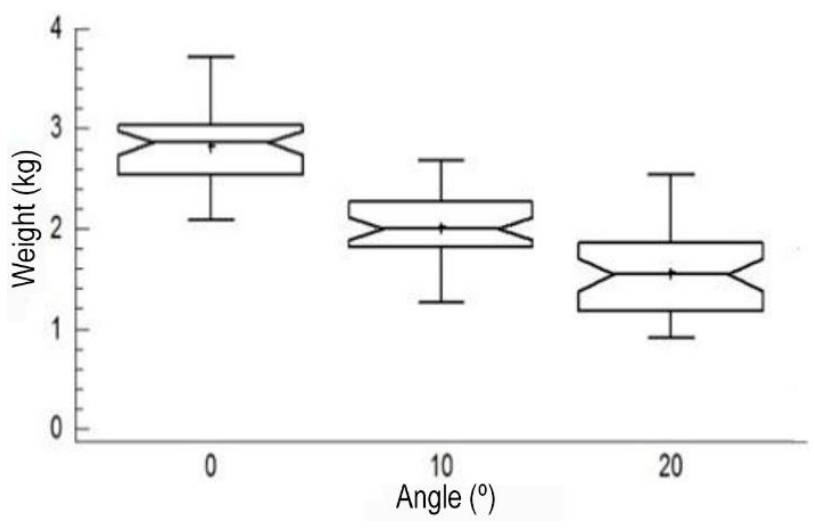

Figure 2. Weight values variation against different sail attack angles $(\beta)$ in a square shape deadweight model.

Regarding the scales, the weight averages, before different vertical attack angles $(\theta)$, derived from the ARs, were $1 / 2.5=2.11 \mathrm{~kg} ; 1 / 3.0=2.16 \mathrm{~kg} ; 1 / 3.5=2.32$ $\mathrm{kg}$ and $1 / 4.0=1.91 \mathrm{~kg}$. The $\mathrm{KW}$ contrast did not detect significant differences between the values measured at different AR $(\mathrm{KW}=6.22 ; P>0.05)$. The box-andwhisker plots show no difference between the medians of the weight values (Fig. 3). 


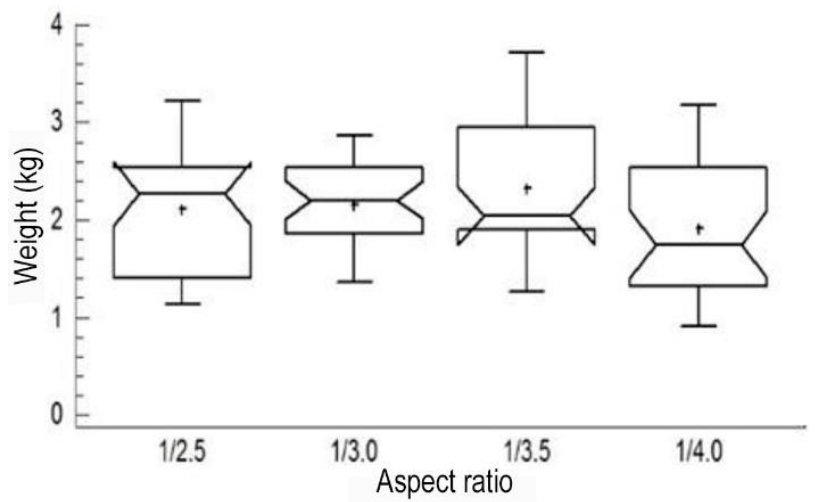

Figure 3. Weight values variation against different aspect ratios in a square shape deadweight model.

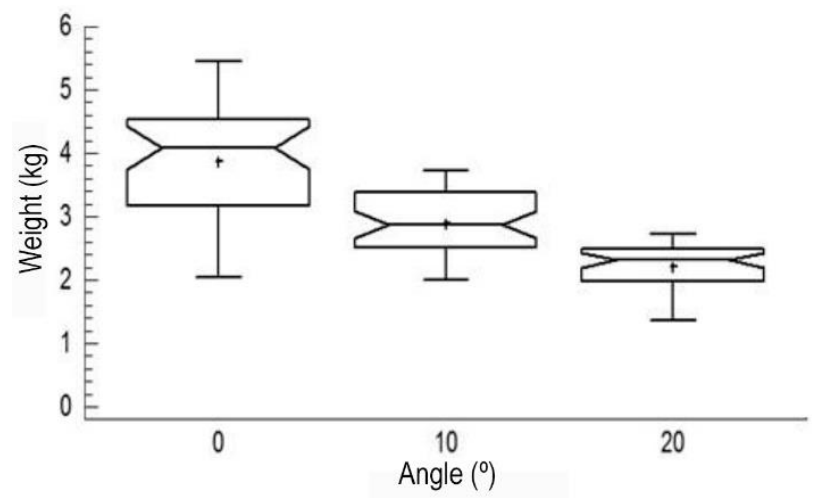

Figure 4. Weight values variation against different sail attack angles $(\beta)$ in a pyramidal shape with a claw structure deadweight model.

The pyramidal model with iron claw structure (Adapted from Concha, 1997)

The average weight values, in the different sail attack angles $(\beta)$, were $0^{\circ}=3.78 \mathrm{~kg} ; 10^{\circ}=2.88 \mathrm{~kg}$; and $20^{\circ}=$ $2.22 \mathrm{~kg}$. When comparing the medians of the values measured on each angle, there is a significant difference (KW $=70.693 ; P<0.05)$, between the three groups of values, being necessary greater $\mathrm{kg}$ to move the deadweight type model with claw structure, at $0^{\circ}$ angle and lower at $20^{\circ}$ angle (Fig. 4).

Regarding the scales, the weight averages, before different angles of vertical attack $(\theta)$ derived from the RAs, were $1 / 2.5=3.05 \mathrm{~kg} ; 1 / 3.0=3.15 \mathrm{~kg} ; 1 / 3.5=3.12$ $\mathrm{kg}$; and $1 / 4.0=2.64 \mathrm{~kg}$. The KW contrast did not detect significant differences between the values measured at different scales (KW $=4.81 ; P>0.05)$. The box-andwhisker plots show no difference between the medians of the weight values (Fig. 5).

The pyramid-shaped deadweight model with blade structure (Adapted from Carroza (1990))

The measurements in $\mathrm{kg}$ needed to move the pyramidal model with blade structure, before sail attack angles

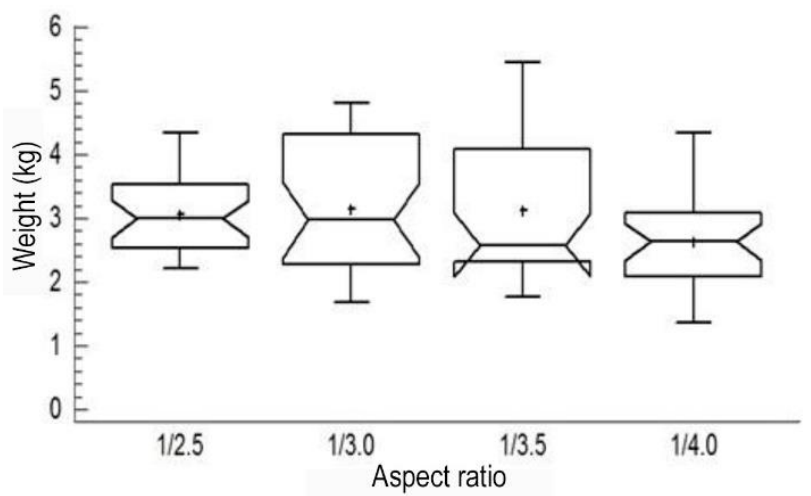

Figure 5. Variation of the weight values against different aspect ratios in a deadweight model of pyramidal shape with claw structure.

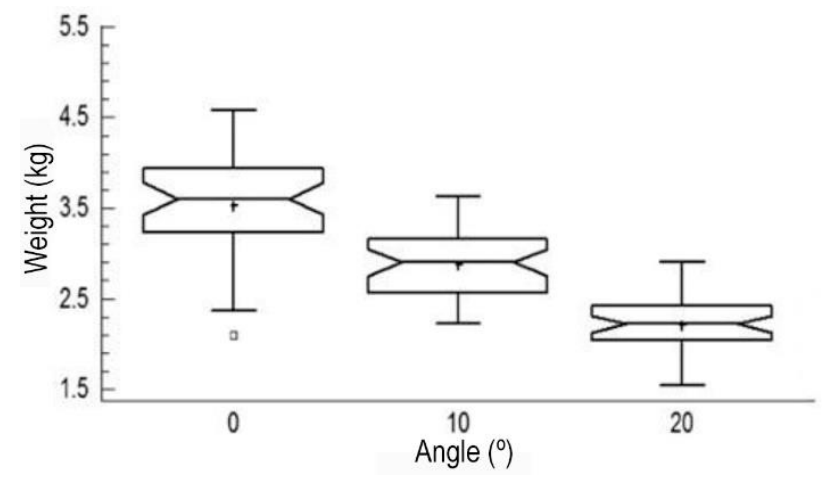

Figure 6. Variation of the weight values against different sail attack angles $(\beta)$ in a pyramid-shaped deadweight model with blade structure.

$(\beta)$, averaged $3.5 \mathrm{~kg}$ in the $0^{\circ}$ angle, $2.87 \mathrm{~kg}$ in the $10^{\circ}$ angle, and $2.21 \mathrm{~kg}$ in the $20^{\circ}$ angle. The Kruskal-Wallis test determined that there is a significant difference between the weights $(\mathrm{KW}=74.399 ; P<0.05)$; that difference was located between the three groups of values (Fig. 6).

As for the scales, the weight averages, faced with different vertical attack angles $(\theta)$, derived from the AR, were $1 / 2.5=3.00 \mathrm{~kg} ; 1 / 3.0=2.51 \mathrm{~kg} ; 1 / 3.5=3.09$ $\mathrm{kg}$ and $1 / 4.0=2.87 \mathrm{~kg}$. The $\mathrm{KW}$ contrast detected significant differences between the values measured at different scales $(\mathrm{KW}=4.81 ; P<0.05)$. The box and whisker plot shows that the difference originated the values measured in the scale 1/3.0 (Fig. 7).

\section{The simple pyramidal model (Adapted from Ogg, 1969)}

For the different angles of attack used in the experience with the simple pyramidal model, before sail attack angles $(\beta)$, the averages were $0^{\circ}=1.69 \mathrm{~kg} ; 10^{\circ}=1.68$ $\mathrm{kg}$; and $20^{\circ}=1.27 \mathrm{~kg}$. The Kruskal-Wallis contrast detected significant differences between the medians of the weights obtained in the three angles $(\mathrm{KW}=29.21$; 


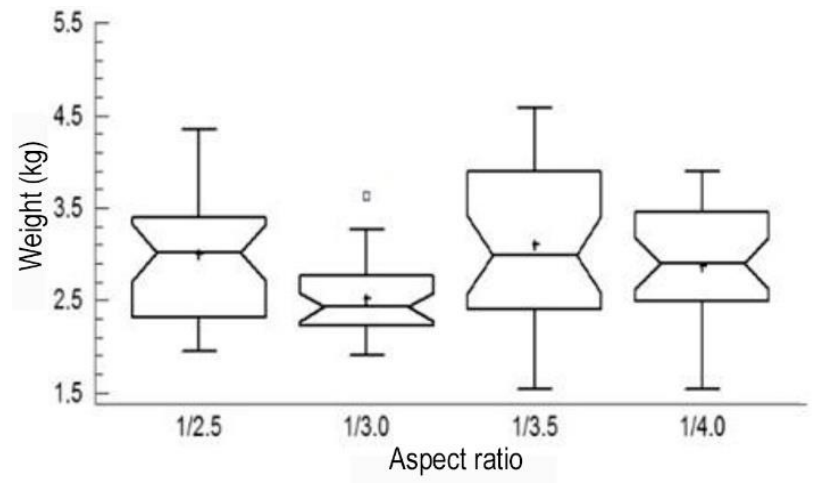

Figure 7. Variation of the weight values against different aspect ratios in a deadweight model of pyramidal shape with blade structure.

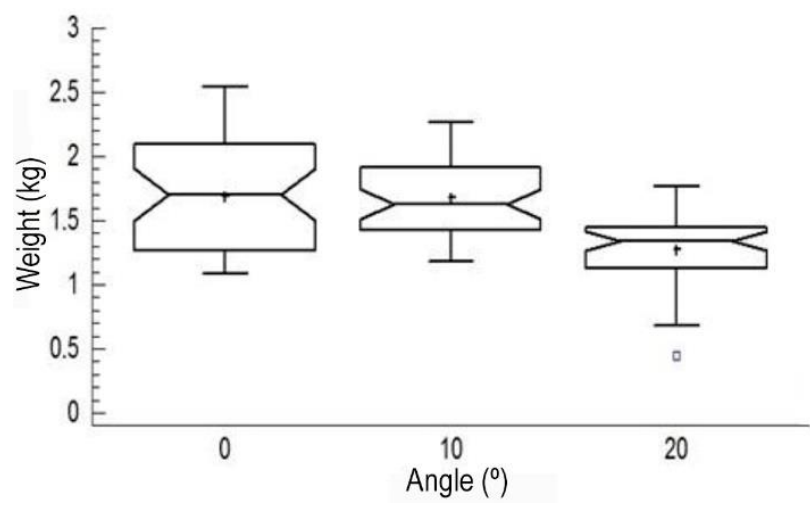

Figure 8. Variation of the weight values against different sail attack angles $(\beta)$ in a deadweight model of pyramidal shape.

$P<0.05)$. It was determined using the box and whisker plot as a posteriori test that the difference originates the values measured in the $20^{\circ}$ angle of attack, where it would have a lower grip (Fig. 8).

As for the scales, the weight averages, faced with different vertical attack angles $(\theta)$, derived from the $\mathrm{AR}$, were $1 / 2.5=1.31 \mathrm{~kg} ; 1 / 3.0=1.91 \mathrm{~kg} ; 1 / 3.5=1.36$ $\mathrm{kg}$; and $1 / 4.0=1.63 \mathrm{~kg}$. The $\mathrm{KW}$ contrast detected significant differences between the values measured at different scales $(\mathrm{KW}=45.447 ; P<0.05)$. In the box and whisker plot, the difference is caused by the values in the $1 / 3$ scale, which are relatively high. Also, the values in the 1/2.5 scale are relatively low (Fig. 9).

\section{The traditional "rezon" model of Margarita Island}

The weight values needed to move the "rezon" type model, before sail attack angles $(\beta)$ averaged, for the $0^{\circ}$ angle $=3.08 \mathrm{~kg}$, for $10^{\circ}=2.91 \mathrm{~kg}$, and for $20^{\circ}=1.75$ $\mathrm{kg}$. The KW contrast detected a significant difference between the median values (KW $=52.615 ; P<0.05)$. The box and whisker plot show that the values were significantly different for the three angles, with $0^{\circ}$ showing the highest values (Fig. 10).

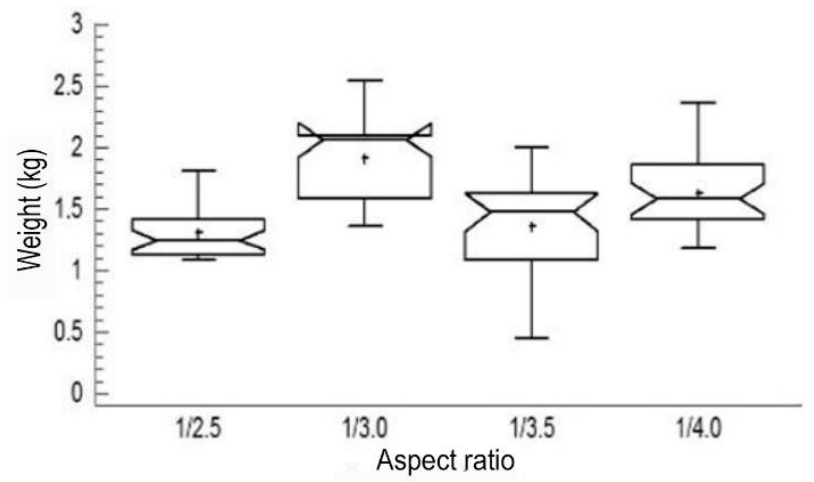

Figure 9. Variation of the weight values against different aspect ratios in a pyramid deadweight model.

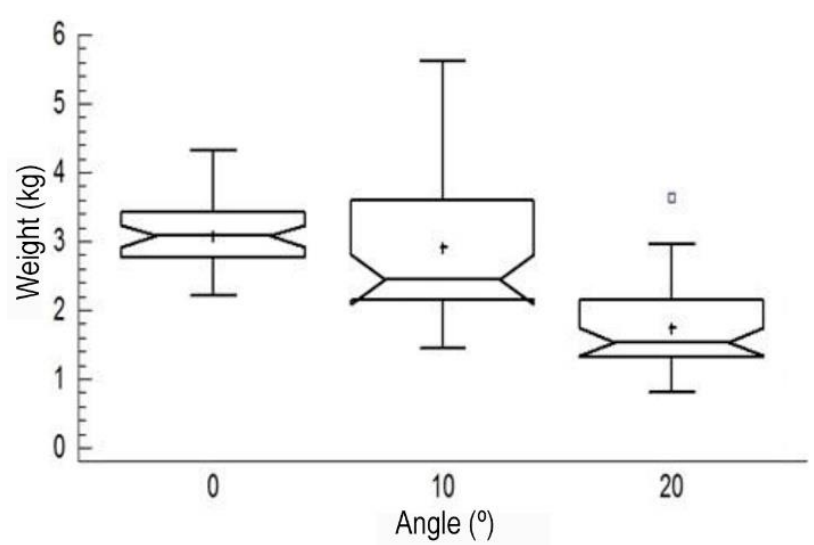

Figure 10. Variation of the weight values against different sail attack angles $(\beta)$ in a deadweight model type rezón.

Regarding the scales, the weight averages for the AR were $1 / 2.5=2.15 \mathrm{~kg} ; 1 / 3.0=2.46 \mathrm{~kg} ; 1 / 3.5=3.45$ $\mathrm{kg}$; and $1 / 4.0=2.26 \mathrm{~kg}$. The $\mathrm{KW}$ contrast detected significant differences between the values measured at different scales $(\mathrm{KW}=27.909, P<0.05)$. The box and whisker plot shows that the difference originated the values measured in the scale $1 / 3.5$, relatively high values (Fig. 11).

\section{The hollow pyramidal model with a vacuum (Adapted from Yokota, 1980)}

For the pyramid type model, provided with a hole in the bottom (hollow), the values in $\mathrm{kg}$ averaged for $0^{\circ}=0.52$ $\mathrm{kg}$, for $10^{\circ}=0.53 \mathrm{~kg}$, and for $20^{\circ}=0.39 \mathrm{~kg}$. The Kruskal-Wallis contrast detected significant differences between the medians of the measured values $(\mathrm{KW}=$ 14.717; $P<0.05$ ); this difference originated from the relatively low values measured at the $20^{\circ}$ angle (Fig. 12).

On the other hand, for the different scales, the averages for the AR were $1 / 2.5=0.46 \mathrm{~kg} ; 1 / 3.0=0.31$ $\mathrm{kg} ; 1 / 3.5=0.48 \mathrm{~kg}$; and $1 / 4.0=0.67 \mathrm{~kg}$. The $\mathrm{KW}$ test detected significant differences between the medians of the measured values ( $\mathrm{KW}=64.873, P<0.05)$. This 


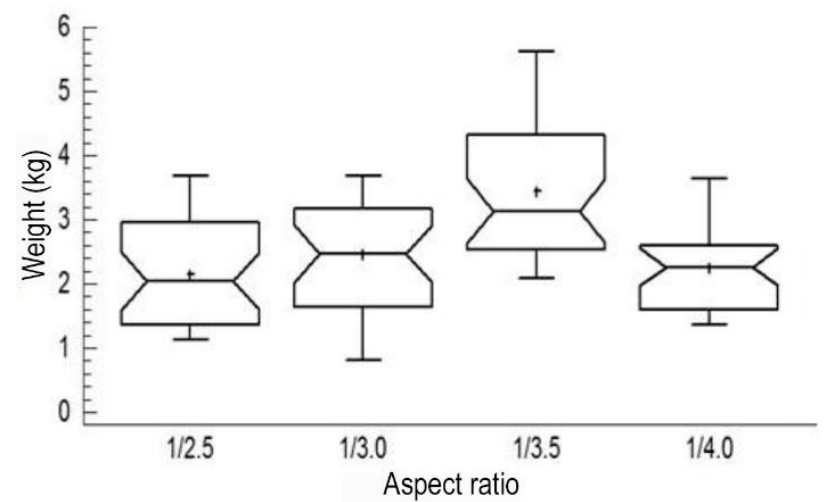

Figure 11. Variation of the weight values against different aspect ratios in a deadweight model type "rezon".

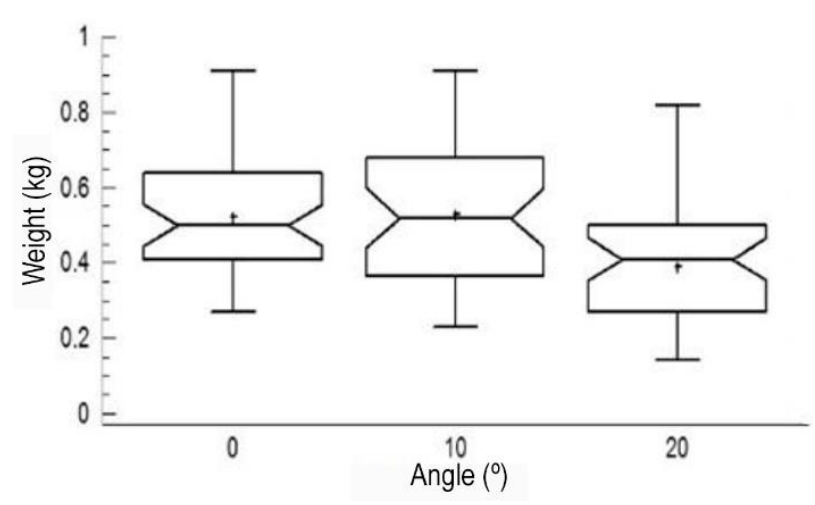

Figure 12. Variation of the weight values against different sail attack angles $(\beta)$ in a pyramid-type deadweight model with a vacuum.

difference was positioned mainly between the values measured in the $1 / 4.0$ angle, relatively higher than the others (Fig. 13).

Finally, the summary of the weight values $(\mathrm{kg})$, necessary to move the different anchor models, applying different sail attack angles $(\beta)$ and at different AR, are shown in Table 2.

\section{DISCUSSION}

For a sandy bottom, the most effective model was the pyramidal with the claw-like frame, followed by the pyramidal with a shovel-like frame and the five-nailed "rezon" anchor, which are traditionally used in Margarita Island.

The metal frames of the deadweight models and the nails of the "rezon" type anchor used as a model, caused a stronger grip when buried in the sandy bottom of the test tank.

Other models, such as the square, the pyramid without a frame, and the hollow pyramid, were not effective in the grip in a sandy bottom, because they required little tension to break their static balance.

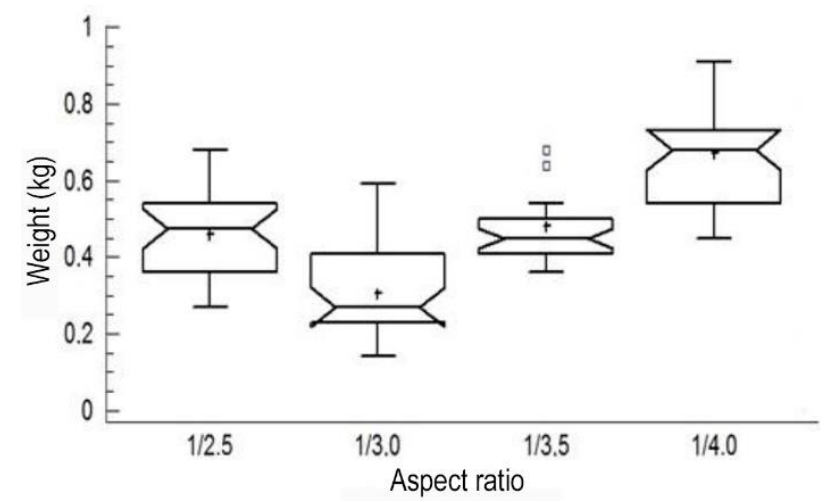

Figure 13. Variation of the weight values against different aspect ratios in a pyramid-type dead with a vacuum.

As for the hollow pyramid model, there was no greater grip because the hole at the bottom did not act as a suction cup as it happens in muddy bottoms (Concha, 1997). But it moved on very fine sand, reducing its friction due to the loss of the contact surface on this type of substrate.

On the other hand, in the experimental design of the investigation, it was not expected that models would bury at the bottom of the test tank, an effect that occurs in practice after months of being placed in the sea. In this regard, the project did not contemplate building other test tanks, hoping that each scale design, in each tank, would have experienced this effect.

About the sail attack angle $(\beta)$, representing the deviation of the current direction, all models tended to lose effectiveness when increasing this variable. It coincided with that indicated by Berteaux (1976); the loss of effectiveness is less notable in the anchor models of the dynamic type, corresponding with that reported by Childers (1973), as were the models with a claw, with a shovel or the type "rezon" anchor.

The scales or aspect ratio (AR) presented variable results. It is worth mentioning that this parameter is important because, with a smaller AR, the tension transmission becomes more direct than when using more loafed AR. Besides, it is worth mentioning that a greater AR will lead to higher material costs and require a more extensive area for cultivation line (Carroza, 1990), especially if this was the case that the competent authority granted these spaces.

According to the calculation of the efficiency index (IA), which indicates the holding property of deadweight in the bottom relative to its weight, the models that turned out to be the most effective in the analysis are shown, in order of efficiency, in Table 1. It was found that the operation of a long line with $\mathrm{AR}=$ $1 / 3$ turned out to be the best option in terms of effectiveness and economy for these types of anchoring. 
Table 2. Summary of weight values of the models against different attack angles $(\beta)$ and aspect ratios.

\begin{tabular}{lcccccccc}
\hline \multirow{2}{*}{ Anchoring model } & \multicolumn{3}{c}{ Attack angles $(\beta)$} & & \multicolumn{3}{c}{ Aspect ratios } \\
\cline { 2 - 5 } \cline { 7 - 9 } & $0^{\circ}$ & $10^{\circ}$ & $20^{\circ}$ & & $1 / 2.5$ & $1 / 3.0$ & $1 / 3.5$ & $1 / 4.0$ \\
\hline Simple truncated pyramid & 1.69 & 1.68 & 1.27 & & 1.31 & 1.91 & 1.36 & 1.63 \\
Simple truncated pyramid with claw & 3.78 & 2,88 & 2.22 & & 3.05 & 3.15 & 3.12 & 2.64 \\
Truncated pyramid with a shovel & 3.50 & 2.87 & 2.21 & & 3.00 & 2.51 & 3.09 & 2.87 \\
"Rezon" & 3.08 & 2.91 & 1.75 & & 2.15 & 2.46 & 3.45 & 2.26 \\
Square & 2.82 & 2.00 & 1.56 & & 2.11 & 2.16 & 2.32 & 1.91 \\
Hollow truncated pyramid & 0.52 & 0.53 & 0.39 & & 0.46 & 0.31 & 0.48 & 0.67 \\
\hline
\end{tabular}

Regarding the dead weight's density, the construction of the experience, fixed proportions of a mixture of four parts of sand, two parts of gravel, and one part of cement (relative density of $\approx 2.400 \mathrm{~kg} \mathrm{~m}^{-3}$ ) were handled. However, the final weights varied because molds used were completed with a greater or lesser mixture volume, according to their shapes and the iron-binding elements.

\section{ACKNOWLEDGMENTS}

The present investigation was carried out thanks to the Research Council of the Universidad de Oriente financing, within the framework of the Project "Study of the behavior of several deadweight anchoring designs for longline type flexible culture structures using scale models, Code CI -6-030602-1665/2010. Thanks to Br. Merving F. Gómez for his valuable collaboration in the simulation tests during the development of the project.

\section{REFERENCES}

Baranov, F.I. 1977. Selected works on fishing gear. Commercial fishing techniques. Israel Program for Scientific Translation, Jerusalem.

Barrientos, J.L. 2000. Diseño de un sistema de fondeo de peso muerto para el anclaje de un longline de cultivo. Tesis Ingeniería Pesquera, Pontificia Universidad Católica de Valparaíso, Valparaíso, 112 pp.

Berteaux, H. 1976. Buoy engineering. John Wiley \& Sons, New York.

Berteaux, H. 1991. Coastal and oceanic buoy engineering. Book published by the author, New York.

Beveridge, 1987. Cage aquaculture. Blackwell Publishing, New Jersey.

Carroza, L. 1990. Determinación de una metodología para la selección y dimensionamiento de un sistema de anclaje para un long-line de cultivo. Tesis Ingeniería Pesquera, Pontificia Universidad Católica de Valparaíso, Valparaíso, 194 pp.
Cochran, W. 1963. Wiley series probability and mathematical statistics-applied. John Wiley \& Sons, New York.

Concha, M. 1997. Estudio de comportamiento de agarre de diferentes diseños de anclaje utilizando modelos a escala. Informe Práctica Profesional II, Ingeniería Pesquera, Pontificia Universidad Católica de Valparaíso, Valparaíso, $61 \mathrm{pp}$.

Childer, M. 1973. Mooring system in hostile water. Petroleum Engineering, 45(5): 58-70.

Fridman, A.F. 1981. Teoría y diseño de artes de pesca industrial. Industria Liviana y Alimenticia, Moscú.

Fridman, A.F. 1986. Calculation for fishing gear designs. FAO fishing manual for fishing books. Fishing news books, Farnham.

López, J., Hurtado, C., Gómez, A., Zamora, V., Queirolo, D. \& Gutiérrez, A. 2017. Stress analysis of a submersible longline culture system through dynamic simulation. Latin American Journal of Aquatic Research, 45(1): 25-32.

Martínez, G. \& Carroza, L. 1992. Configuración del cabo de fondeo de un longline de cultivo a través de la simulación análoga. Investigaciones Marinas, Valparaíso, 20: 55-66.

Merino, G., 1997. Considerations for longline culture systems design: scallop production. In: Helsley, C.E. (Ed.). Open ocean aquaculture '97, charting the future of ocean farming. Proceedings of an International Conference, April 23-25, 1997, Maui, Hawaii. University of Hawaii Sea Grant College Program \#CP98-08, pp, 145-154.

Merino, G., Cortés-Monroy, J., Abarca, A. \& Barraza, J. 2001. Diseño y operación de sistemas de cultivo. In: Maeda-Martínez, A.N. (Ed.) Los moluscos pectínidos de Iberoamérica: ciencia y acuicultura. Editorial Limusa, Ciudad de México, pp. 375-404.

Ogg, R. 1969. Anchors. In: Myers, J., Holm, C. \& McAllister, R. (Eds.). Handbook of ocean and underwater engineering. McGraw-Hill, New York, pp. 70-74. 
Sokal, R.R. \& Rohlf, F.J. 1995. Biometry: the principles and practice of statistics in biological research. W.H. Freeman, New York.

Trujillo, E., Martínez, G. \& León, L. 2007. Dimensionamiento y configuración teórica de una línea de cultivo de Ostra perla (Pinctada imbricata Mollusca: Bivalvia), en la bahía de Charagato, Isla de Cubagua, Venezuela. Investigaciones Marinas, Valparaíso, 35(1): 39-54.

Received: 2 May 2019; Accepted: 17 June 2020
Voinikanis-Mirskii, V.N. 1979. Teoría y diseño de artes de pesca industrial. Material didáctico. Instituto Tecnológico de la Industria y Economía Pesquera, Ministerio de Pesquería URSS, Astrakhan.

Yokota, E. 1980. Diseño de una balsa industrial para el cultivo artificial de chorito como una alternativa para la industria conservera de Calbuco. Tesis Ingeniería Pesquera, Pontificia Universidad Católica de Valparaíso, Valparaíso, 112 pp. 